\title{
UMA VOZ EM ESTILHAÇOS: O QUE FICA? (A PROPÓSITO DE 5 HOMEÓSTATOS DE JOSÉ ALBERTO MARQUES)
}

\author{
Maria do Carmo Castelo Branco de Sequeira*
}

RESUMO: Fixando-nos em apenas cinco homeóstatos de José Alberto Marques e procurando neles a simbólica desse número, tentámos interpretar o processo de criação poética do autor, enquanto combinatória de dois sistemas de signos (linguísticos e figurativos), perscrutando, na sombra dessa poética, a projecção de um futuro electrónico.

Palavras-chave: Homeóstatos. José-Alberto Marques. Poesia Experimental Portuguesa.

A.

Comecemos, em tom de leitura primária, identificadora, por seguir 5 dos homeóstatos de José Alberto Marques, não arbitrariamente escolhidos, como iremos esclarecendo, mas tentando verificar, em paralelo, se o número "cinco" continua a ser, de facto, o símbolo do equilíbrio, da harmonia (patente, não por acaso, nas catedrais góticas), ou se é, igualmente, o desestabilizador dessa ordem, ou, em última análise, o que desenha, praticando, a pretensão de quebrar todos os sinais de ligação arquitextual.

Homeóstato 1. "Sem luz. a noite acontece. ventre escuro. sombra: neve. alguém: o teu grito..."

*Universidade Fernando Pessoa, Portugal. E-mail: mcseq@ufp.edu.pt

\section{(cc) EY-NC-ND}

Esta obra está licenciada com uma licença Creative Commons. 
Fig. 1 - Homeóstato 1, José-Alberto Marques, 1965. Imagem de Operação 1 (1967). Também publicado em Poesia Experimental 2 (1966); Antologia da Poesia Concreta em Portugal (1973); Antologia da Poesia Experimental Portuguesa Anos 60 - 80 (2004).

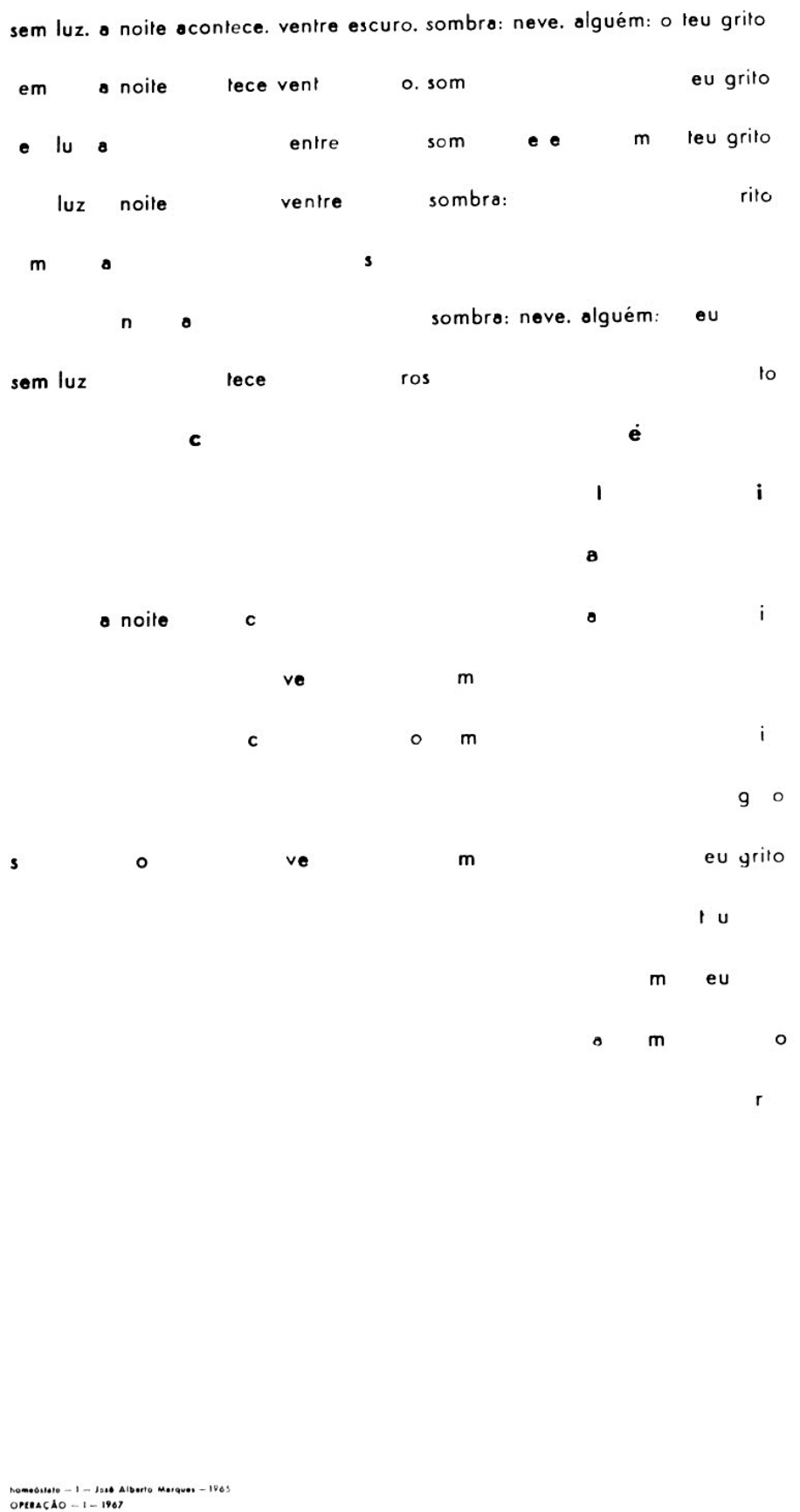


... Por vezes, como aqui, a poesia constrói-se a partir do Caos, num grito que a transforma em Verbo, em Logos, no Poema.

Começa por instituir, pausadamente, uma narrativa, dá-lhe sequência breve, quase nominal, mínima, para logo a interromper e rapidamente a destruir com a força de um inesperado Apocalipse - Apocalipse que transforma as letras, os vestígios de uma sílaba ou de uma palavra em pictogramas esfarelados, sombras da cor de uma unidade perdida, obrigando-nos, assim, a entrar num caos de fragmentos, de estilhaços onde mesmo a leve sombra do simbólico, dificilmente, se manifesta.

Porém, não refeitos ainda, da destruição, logo começamos a descortinar nela significações expressivas, onde os sujeitos voltam a instalar-se e a reunirem-se na sombra, tornados forças verbais transformadoras, que mostram, primeiro alguém, saído da sombra, do frio (da neve), para se ir definindo como um "rosto" que se tece. Então, num ritual amoroso, o grito transforma-se em nova frase: que se alonga verticalmente...

"a noite /ve m /c o m i/go /

só ve m"
eu grito
tu
m eu/
a m

... e o texto, recuperado inteiro, assume-se na verticalidade reveladora do triângulo, completando-se, ou encontrando, na nossa interpretação, o seu fechamento semiótico.

\section{Homeóstato 2}

Outras vezes, porém, o texto estende-se numa rede de lexemas, em desagregação iniciática mas legível, onde a desordem se manifesta como aparência (deslocada, espraiada), enquanto vai formalizando a isotopia do calor fervilhante, em progressão sensível e determinada (teu sonho lento / o teu sonho quente/ ver teus sonhos de 
lume), para se erguer /refazer com intensidade maior, na declaração final (?), vermelhos teus sonhos de lume: liberdade quente...

Fig. 2 - Homeóstato 2, José-Alberto Marques, 1965. Imagem de Operação 1 (1967). Também publicado em Antologia da Poesia Concreta em Portugal (1973).

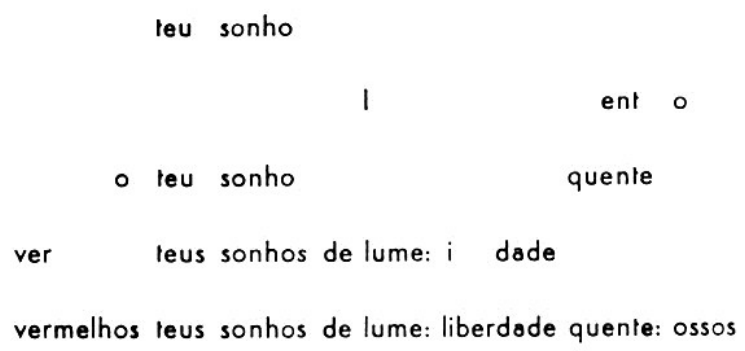

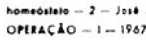

Texto Digital, Florianópolis, Santa Catarina, Brasil, v. 12, n. 1, p. 79-91, jan./jun. 2016. ISSNe: 1807-9288. 
... para logo se diluir, porém, por quebra de iteração e de repentina e opositória fuga semântica, para se fixar num outro quadro isotópico, oposto, sintético e disfemicamente agressivo: ossos - como se a cadeia simbólica que formalizava a ideia crescente da paixão, se isolasse brutalmente numa finda irreversível: a Morte, concretamente representada, como se quisesse recuperar intertextualmente e no seu inverso mais duro, o soneto anteriano, "Mors - Amor".

\section{Homeóstato 3}

Outras vezes, ainda, o poema ergue-se, a princípio, como espécie de descrição, ou avaliação sumária, ou mesmo (se "abstractizarmos" o concretismo dos constituintes) como tema alongado, existencial, mas firmemente nominal, telegráfico e próximo: estas grades. a rua. portos e peitos mas. nossa a vida. 
Fig. 3 - Homeóstato 3, José-Alberto Marques, 1965. Imagem de Operação 1 (1967). Também publicado em Antologia da Poesia Concreta em Portugal (1973); Antologia da Poesia Experimental Portuguesa Anos 60 - 80 (2004).

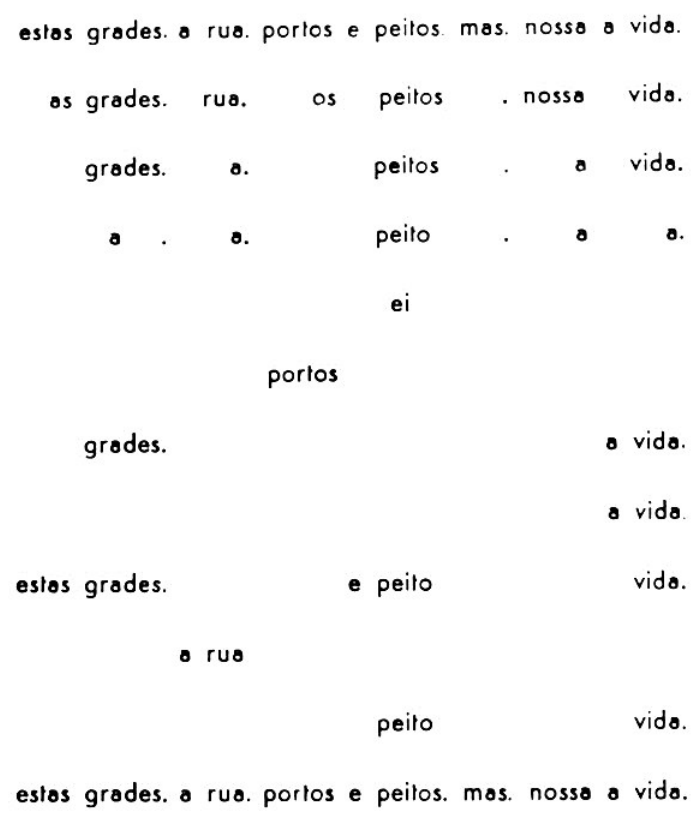


Depois, como para recolher o material linguístico envolvido e alcançar o seu possível sentido, desagrega-se em secções verticais, onde surgem, como que caoticamente, recolhas lexicais aparentemente ao abandono, em movimento progressivo, mas variável:

- Assim, essa aparente desagregação, percorre e quase esgota todos os determinantes, desde o artigo definido, à utilização do morfema zero, ou isolando uma vogal central integrante do nome (começando, assim, a interiorização), para chegar progressivamente ao deíctico reforcivo da proximidade e da ligação ao sujeito: as grades / grades /gr[a]des (a) / grades / estas grades;

- Igualmente no plano de uma sensível interiorização, vai progressivamente transformando a sinédoque em metáfora, através da reiteração das variáveis do nome "peito": Começa pelo plural reiterado, retoma o singular; isola igualmente (retirado do centro da palavra), não uma vogal, mas um ditongo; para logo acrescentar (juntando, através da copulativa) o singular duplicado (singularizado) do nome: peitos / peitos /peito // p[ei]to (ei) // e peito /peito;

- A progressiva assimilação de dois sujeitos erguidos das palavras permite e explica o deíctico possessivo, nossa, para que se reencaminham outros espaços: o nome singular, primeiro, em morfema zero, rua, para logo se individualizar em a rua, bem como o plural portos (em coluna centralizada) e, depois e fundamentalmente, a coluna final, reiterativa do signo vida, tanto a determinando como substância simples (a vida), como a generalizando (vida).

- Assim, estas falsas colunas, aparentemente colhendo seccionalmente as variantes lexicais, vai conjugando, de forma gradativa variantes de variantes, para as reencontrar, especularmente e já implicitamente "explicadas", na frase final, não sem antes nos oferecer o nó significativo que faltava: os dois campos isotopicamente opostos: o que está fora, estranho, quase obstáculo: (grades, rua); e o que está dentro (peito, vida). Será, porém, o lexema porto (com o seu sentido de chegada e possibilidade de encontro) que, apesar da interrupção sonora provocada pela proximidade de oclusivas iniciais (portos e peitos), permite, por força da continuidade articulatória labial e pela aliteração 
que os une, criar a necessária sequencialidade (o caminho) para o deíctico acolhedor, "nossa vida".

\section{Homeóstato 9}

Diferente dos anteriores, porque, paradigmático da ligação cratiliana da palavra ao referente, este homeóstico procura desenhar essa mesma íntima relação, negando a arbitrariedade sígnica. De facto, não lemos, olhamos simplesmente e ouvimos o som, combinando sinestesicamente os sentidos e cineticamente sentindo o movimento.

Fig. 4 - Homeóstato 9, José-Alberto Marques, 1965. Imagem de Operação 1 (1967). Também publicado em Antologia da Poesia Concreta em Portugal (1973).

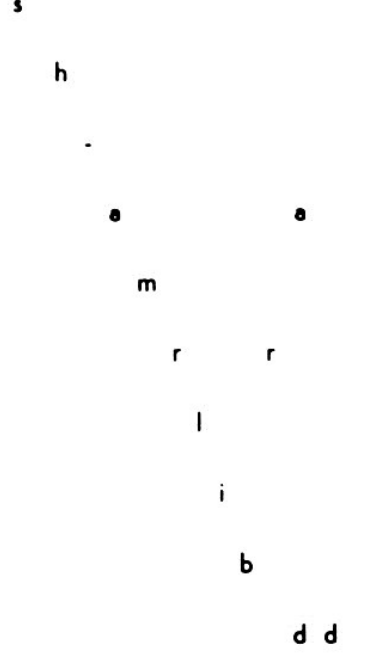


Assim, por um lado, as letras, em diagonal, que formariam o vocábulo VENTO, combinam no próprio seio da palavra, a constritiva labial que se repercute no som nasal sequente, para encontrar o tom interceptador da oclusiva dental " $\mathrm{t}$ ", encaminhando-se ambas para a representação verbal do som (espécie de onomatopeia imitativa pura), através da união da sibilante com o mudo $\mathbf{h}$, como que criando um inovador grupo chiante (sh).

Por outro lado (e paralelamente), a fuga do centro da construção da imagem de certos sons nasais prolongados, como acontece com a ligação, e... $\mathbf{n}$, ou do o que termina o nome "vento" e que se percute como semi-vogal (u) - essa fuga, dizíamos, imita um crescendo sonoro que se alonga em direcção horizontal e vem encontrar, já mais perto de nós, outros sons fortes, isolados e novos - enquanto combinatórias de consoantes lábio-dentais - sons que nos alcançam e, de repente, nos põem, diante dos olhos, um movimento - aquele que gera o som - e que parece sair da página e vir directo a nós, como uma pancada.

\section{Homeóstato A}

Finalmente, uma última (talvez a mais bela) perspectiva de "ruína textual" que se repercute nos "homeóstatos" de José Alberto Marques:

\footnotetext{
"a secura da pedra da catedral antiga tem veios na garganta e escuta

a voz misteriosa do silêncio que ao soar reflecte o vento do tempo, do tempo em o grito lento"
} 
Fig. 5 - Homeóstato A, José-Alberto Marques, 1993. Imagem de Imaginários de ruptura (2002).

a secura da pedra da catedral antiga tem veios na garganta e escuta a voz inisteriosa do silêncio que ao soar reflecte o vento do tempo, do tempo em 0 grito lento
a $\mathrm{e}^{\mathrm{a}} \mathrm{a}$
a a
a
e

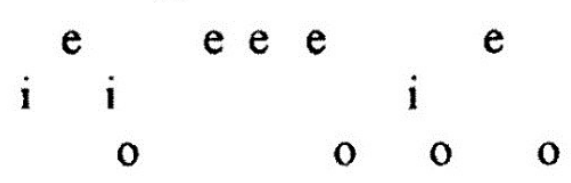

u

a secura da pedra

a

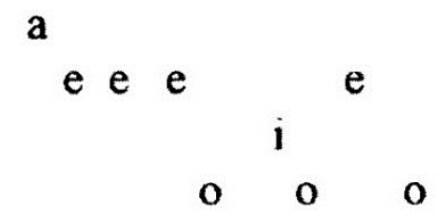

a voz misteriosa

a $\quad$ a $\quad$ a $\quad$ a

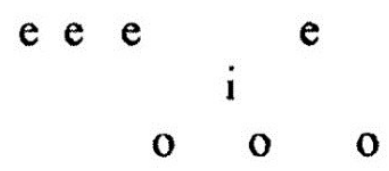

u

reflecte
a $\quad e^{a} e^{a}$
o
$\mathrm{i}^{\mathrm{e}} \mathrm{i} \quad \mathrm{i}^{\mathrm{e}}$
0
$\begin{array}{lll}0 & 0\end{array}$
$\checkmark$ grito lento
a
a a e $^{\text {a a }}$
a
a
e e e e
0
0
$\mathbf{u}$

"Homeóstato - A", 1993 
Saído de uma frase (quase síntese ou envoltório), como o 1 e o 3, mas mais longa, esta, e construída em dois tons e não equivalentes valores sintácticos - facto que a alternância da escrita normal e do negrito tornam evidente -, este homeóstato poderia pressupor um caminho semelhante de expressão visualizada que iria encontrar a sua própria finda por processos equivalentes: ou como conclusão/expansão dos dados iniciais, ou como total reiteração destes.

Aqui, porém, o caminho é diferente, desdobrando-se em socalcos que cortam a página em diagonal, para reconstituírem, despida dos determinativos, a frase nua que a escrita normal desenhara, reduplicando, agora, o seu posicionamento original:

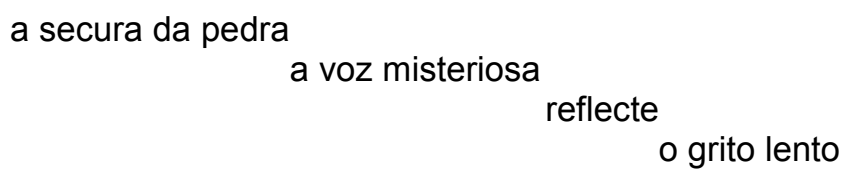

Esta reconstituição nua dos constituintes principais da frase, não se opera, porém, sem um movimento de expansão/libertação simulada e caótica das vogais que vão preenchendo os espaços vazios da página, como que sugerindo visualmente a passagem da História, que só pode ser recuperada como leve vestígio ou "como grito lento".

Entretanto, como se fossem dados desnecessários (e opondo-se ao reforço de importância simbólica que o negrito parecia conceder-lhes) a página liberta-se (sem totalmente se libertar, mas omitindo-a como desnecessária) da marca temporal, da memória, que palavras como "catedral antiga", "silêncio", "vento do tempo, do tempo", referenciavam. A secura (da pedra), o mistério (da voz), o grito (reprimido) mantêmna, de facto, latente...

B.

Acrescentemos agora, muito rapidamente, muito sumariamente, o que esta "poética" latente, subjacente a todos estes homeóstatos pode reunir (agregar) das possíveis 
"regras" significantes, aqui de certa forma, visualizadas, sob a superfície dos textos poéticos:

- Em primeiro lugar, a concretização de uma poética de significantes que, explorando a construção da página, pressupõe não só a omissão, como também o ressurgimento de uma história da poética, e ainda o futuro das linguagens poéticas electrónicas;

- Dentro desta ideia englobante, a re -descoberta aparente de um dispositivo de ruptura, de um corte estético, tratados como quase imposição, mas também como "defesa" do novo, não considerado individualmente, mas alargado aqui à evolução geral da Poética - dispositivo que poderíamos integrar naquela espécie de "angústia" que Harold Bloom designou por Knosis (1991, p. 28) e onde, de forma subtil, se enquadra o último homeóstato.

- No plano interno, o avivar de uma nova sintaxe que utiliza não só a palavra, mas se estende a outros campos da arte e à recriação da página;

- Neste sentido, a redescoberta de um pensamento visual, no sentido que the dava Melo e Castro (1973, p. 148-149) e, consequentemente, o desenvolvimento das qualidades sensíveis do material sígnico;

- No caso específico destes poemas de José-Alberto Marques, a consciência de "poesia", enquanto destruição, visionada através de aparentes ruínas dispersas, que não perdem, todavia, o seu sentido e a sua beleza - a sua verdade, no sentido que Guilherme Ihe dava no fim de O Nome da Rosa ("Nunca duvidei da verdade dos signos, são a única coisa de que o homem dispõe para se orientar no mundo. Aquilo que nunca compreendi foi a relação entre os signos.");

- Por parte do receptor: a transformação da leitura, por exigência de um outro olhar (não só de percurso horizontal, mas de inspecção cruzada e vertical);

- Consequentemente, a exigência genérica desse novo leitor que reúna estas condições (ou desejo) indicadas por Melo e Castro: "o utente do poema que se aperceba das informações de que for capaz". 
Foi essa a nossa tentativa de leitura destes 5 homeóstatos de José Alberto Marques, caminhando no meio das ruínas, mas tentando descortinar nelas, a poiesis, ou os vestígios dos passos do poeta.

\section{A VOICE IN SHARDS: WHAT REMAINS? (WITH REGARD TO 5 HOMEÓSTATOS BY JOSÉ ALBERTO MARQUES)}

ABSTRACT: Settling on just five homeóstatos by José Alberto Marques, and trying to find in them the symbolic nature of that number, we try to interpret the author's process of poetic creation, as the combination of two sign systems (linguistic and figurative), exploring, in the shadow of that poesis, the projection of an electronic future.

Palavras-chave: Homeóstatos. José-Alberto Marques. Portuguese Experimental Poetry.

\section{Referências}

BLOOM, Harold. A Angústia da Influência. Lisboa: Cotovia, 1991.

MELO E CASTRO, Ernesto de. Entrevista a Haroldo de Campos. Antologia da Poesia Concreta em Portugal. Lisboa: Assírio e Alvim, 1973.

Recebido em: 19/05/2016.

Aceito em: 15/06/2016. 